\title{
¿Neuroginecología? El reto de la atención a la mujer con padecimientos neurológicos en el siglo XXI
}

\author{
Neurogynecology? The challenge of care for women with \\ neurological conditions in the 21st century
}

\author{
Marlene Arbeu Reyes* \\ Citar como: Arbeu RM. ¿Neuroginecología? El reto de la atención a la mujer con padecimientos neurológicos en \\ el siglo XXI. Acta Med Grupo Angeles. 2021; 19 (3): 398-400. https://dx.doi.org/10.35366/101737
}

Las mujeres y los hombres tienen diferentes necesidades y problemas de salud, no sólo por sus diferencias biológicas, sino también por el rol específico que la sociedad les ha asignado de acuerdo con los patrones sociales y culturales imperantes; ${ }^{1}$ sin embargo, muchos de los principales riesgos en la salud de la mujer están relacionados con su biología reproductiva, con múltiples implicaciones en el abordaje diagnóstico y terapéutico general, siendo esta situación particularmente llamativa en los trastornos neurológicos.

En México y en el resto del mundo, la neurología de la mujer es un campo poco explorado, y su ejercicio requiere de una aproximación multidisciplinaria, donde la formación permanente de los médicos de primer contacto es fundamental, dado el impacto social que se genera cuando la enfermedad neurológica y sus secuelas están presentes en féminas en edad reproductiva. Se presentan tres ejemplos de la implicación del sexo en el contexto de un padecimiento neurológico subyacente, sin pretender una revisión detallada de las patologías señaladas, sino únicamente colocar tal consideración en el panorama clínico.

Caso 1. Mujer de 23 años, sin antecedentes, desde un mes antes del ingreso sufría desorientación, lenguaje incoherente e irritabilidad, tratada en otra unidad hospitalaria como encefalitis viral, sin reacción a aciclovir; al examen

\footnotetext{
* Médico residente de neurología, Hospital de Especialidades “Dr. Bernardo Sepúlveda" del Centro Médico Nacional Siglo XXI. Especialista en medicina interna. Miembro de la American Academy of Neurology \& Neurocritical Care Society. México.
}

Correspondencia: Marlene Arbeu Reyes

Correo electrónico: marlenearbeur@gmail.com

Aceptado: 11-02-2021.

www.medigraphic.com/actamedica

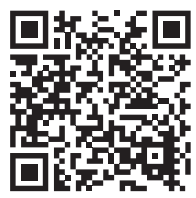

físico revela discinesias persistentes orolingüales, líquido cefalorraquídeo y estudios de neuroimagen normales.

Enfoque basado en el sexo: la encefalitis autoinmune asociada con anticuerpos contra el receptor de N-metil-D-aspartato (NMDA) debe considerarse como sospecha diagnóstica inicial de esta enfermedad en mujeres jóvenes previamente sanas. ${ }^{2,3}$

La encefalitis del receptor anti-NMDA es un trastorno autoinmune bien caracterizado vía manifestaciones psiquiátricas prominentes y disfunción cognitiva, deterioro del habla, convulsiones, discinesias y otras anomalías del movimiento, disminución del nivel de conciencia e inestabilidad autonómica. ${ }^{3,4} \mathrm{El}$ trastorno afecta principalmente a niños y adultos hasta los 45 años; las mujeres podrían padecer un teratoma ovárico asociado, 3,5,6 como en el caso actual.

A su llegada, se solicitó una ecografía pélvica, encontrando un tumor de ovario izquierdo, el cual se resecó con reporte histopatológico de teratoma positivo a anticuerpos anti-NMDA, confirmando la etiología, administrando inmunoterapia con resultado parcial, alternando estabilidad y agitación psicomotriz.

Algunos otros ejemplos de síndromes clásicos de encefalitis paraneoplásica mediada por anticuerpos incluyen: encefalomielitis anti-Hu, a menudo asociada a cáncer de pulmón de células pequeñas (CPCP); encefalitis asociada a Ma2 relacionada con cáncer testicular y encefalomielitis mediadora de respuesta anti-colapsina-5 (CRMP5) conectada a CPCP o timoma.

En el contexto de un síndrome encefalítico bajo sospecha de autoinmunidad, existe un amplio espectro clínico que va desde la encefalitis límbica típica hasta síndromes con síntomas neuropsiquiátricos complejos, por ejemplo: déficit de memoria o cognición, psicosis, convulsiones, movimientos anormales o coma. ${ }^{5}$ Estos trastornos están asociados a anticuerpos contra las proteínas sinápticas o de la superficie de las células neuronales y pueden ocurrir en presencia o ausencia de cáncer. 
La suspicacia clínica debe ser alta, buscando orientar el dictamen y el tratamiento, pues es una patología reversible y recuperable. Probablemente, al no encontrarse en el centro de atención inicial familiarizados con el tema, el abordaje diagnóstico fue retrasado, quizá favoreciendo la presencia de secuelas conductuales irreversibles.

Por otra parte, si bien se conjetura que el antecedente de infección desempeña un papel en el desencadenamiento de la encefalitis autoinmune, hasta la fecha esto sólo se ha demostrado para la variante viral por herpes simple (HSVE). Algunos estudios han revelado que aproximadamente entre 20 y $30 \%$ de aquellos pacientes quienes son negativos para el receptor de NMDA en suero y líquido cefalorraquídeo (LCR) en el momento de la infección por HSVE, seroconvierten a anticuerpos positivos para esa proteína receptora (o menos comúnmente a distintos anticuerpos antineuronales), en el contexto de síntomas recurrentes no atribuibles a la recaída de HSVE. Una proporción menor desarrolla el receptor NMDA o diferentes anticuerpos en ausencia de síntomas clínicos. , $^{3,7}$

Caso 2. Fémina de 21 años, con dictamen de epilepsia temporal y electroencefalograma que mostró datos de actividad epileptiforme izquierda; bajo medicación usando valproato desde hace cuatro años, con descontrol en padecimiento a pesar del uso de dosis supraóptimas, incluyendo alteraciones menstruales, aumento gradual de peso e hirsutismo.

Enfoque con base en el sexo: los ciclos anovulatorios, la obesidad y otros datos clínicos de hiperandrogenismo llevaban a la sospecha de síndrome de ovario poliquístico (SOP), el cual ha sido confirmado. En contraste con el uso de otros antiepilépticos, en mujeres tratadas empleando valproato la incidencia de SOP es 1.95 veces superior, generando como efectos secundarios aumento de peso, desarrollo de resistencia a la insulina, hiperestimulación ovárica, hiperandrogenismo y enfermedad de ovario poliquístico. ${ }^{8}$

Las descargas epilépticas focales del lóbulo temporal podrían ejercer una influencia directa en la función del eje hipotalámico-hipofisario, alterando la liberación de hormonas sexuales, en un círculo vicioso de estimulación ovárica, disfunción endocrina y descontrol epiléptico.

La disfunción endocrina reproductiva en féminas con epilepsia es un tema importante, y en estos últimos años ha surgido una evidencia creciente que respalda el efecto sobre tales hormonas, tanto de la epilepsia per se, como de varios fármacos antiepilépticos (FAE). Las descargas epilépticas focales del lóbulo temporal pueden tener un efecto explícito sobre la función del eje hipotalámico-hipofisario, alterando así la producción de hormonas esteroides sexuales. El papel de la lateralidad y la gravedad de la epilepsia todavía es conflictivo. El uso de FAE inductores de enzimas hepáticas, dígase fenobarbital, fenitoína y carbamazepina, puede aumentar las concentraciones séricas de globulina transportadora de esas hormonas, lo que conduce a una disminución de la bioactividad de la testosterona y el estradiol. ${ }^{8,9}$ El ácido valproico, un inhibidor enzimático, se ha asociado con la aparición de trastornos endocrinos reproductivos caracterizados por niveles elevados de: testosterona sérica, índice de andrógenos libres, concentraciones de androstenediona y sulfato de dehidroepiandrosterona, así como con cambios poliquísticos en los ovarios y trastornos menstruales. ${ }^{9,10}$ Una mejor comprensión de los efectos de dichos FAE sobre las hormonas sexuales es clave para seleccionar los FAE adecuados, y es fundamental para la salud reproductiva de las pacientes. ${ }^{10}$

Afortunadamente, al realizar el cambio de antiepiléptico, se logró el control de la epilepsia, además, mediante una orientación multidisciplinaria, se obtuvo una pérdida ponderal gradual mediante cambios en el estilo de vida, consiguiendo asimismo la regularización de su patrón menstrual.

Caso 3. Mujer de 33 años padeciendo cefalea holocraneal severa, náuseas y vómitos siete días después del inicio, sin remisión con analgésicos; reveló incapacidad para emitir lenguaje y debilidad progresiva en hemicuerpo derecho, doce horas después del comienzo del cuadro. Es remitida al hospital bajo presunción de diagnóstico de trastorno funcional, llegando somnolienta, con papiledema. Desde la atención inicial, la paciente había declarado que había estado usando anticonceptivos orales durante tres años. La trombosis del sistema venoso profundo se corrobora mediante resonancia magnética utilizando gadolinio. Perfil de autoinmunidad, ecocardiograma y estudios hematológicos normales.

Posterior al evento, la paciente presentó secuelas a expensas de cefalea crónica, afasia subcortical, y hemiparesia derecha, no densa, pero limitante de las actividades laborales.

Enfoque basado en el sexo: aunque el uso de métodos anticonceptivos altamente efectivos fue un cambio trascendental, que en el último siglo permitió la inclusión de las mujeres en áreas distintas al hogar, ${ }^{1}$ el uso de hormonales, ya sean antigestágenos orales o de reemplazo, es la causa de hasta el $54.3 \%$ de los casos de trombosis venosa cerebral, ${ }^{11}$ que según el estudio RENAMEVASC en México, representa el 3\% de eventos de enfermedad vascular cerebral, teniendo, entre sus posibles orígenes, trombofilias, embarazo y traumatismos. ${ }^{12}$

Se ha informado de un riesgo relativo de tromboembolismo venoso (TEV) de tres a cinco veces mayor en usuarias de anticonceptivos orales combinados (AOC) (todos los tipos). Sin embargo, dado que la tasa de TEV en féminas jóvenes es baja, el peligro absoluto de TEV en usuarias de AOC es de aproximadamente 0.06 por 100 píldoras al año. ${ }^{11,13}$ Esa probabilidad es más elevada en los primeros meses de uso y es considerablemente más baja que la observada 
en el embarazo y el periodo postparto temprano $(0.2$ por 100 años). ${ }^{13,14}$

El riesgo absoluto es más alto entre las mujeres con enfermedades asociadas, como la trombofilia. Otros contribuyentes son los que predisponen a la tromboembolia, incluidos el tabaquismo, la obesidad, el síndrome de ovario poliquístico, la vejez y la inmovilización. ${ }^{14,15}$

\section{CONCLUSIÓN}

Brindar un tratamiento individualizado a cada paciente requiere de una sólida preparación, que de manera simultánea contribuya a erradicar ideas obsoletas y erróneas: la desafortunada tendencia a considerar a la neurología, dada su complejidad, como una entidad aislada, o no relacionada con otras áreas de la medicina (epidemiología, ginecología, endocrinología, y un largo etcétera), teniendo un impacto negativo en la evolución de los y (en aquellos casos anteriores) de las pacientes, dejando de lado que la práctica médica en su más pura esencia ha de ser integral.

Lo anterior sólo pone en evidencia un profundo desconocimiento del sistema de salud, así como de las bases fisiopatológicas de la respuesta del organismo a las diversas noxas y su abordaje farmacológico.

Debido a la heterogeneidad poblacional y la amplitud del conocimiento requerido, tener una formación continua en esta área debería ser un punto importante en la búsqueda de la excelencia en la praxis médica. Existen, de hecho, en Estados Unidos, Canadá y Reino Unido, departamentos dedicados, de forma exclusiva, al estudio y atención de las enfermedades neurológicas en las féminas, considerando que más allá de movimientos políticos, culturales, económicos y sociales que tienen por objetivo la igualdad de derechos entre hombres y mujeres, existen distinciones biológicas que per se, implican el empleo de un enfoque distinto en el tratamiento, el cual sin duda requiere más tiempo y experiencia a fin de resolver los problemas que las aquejan, al igual que las múltiples dudas asociadas a los padecimientos (v. gr. uso y contraindicación de medicamentos durante el embarazo y lactancia, etc.).

Por ello, siendo médicos, en el rol de educadores de las nuevas generaciones, se debe fomentar en ellas el interés por el cuidado integral, así como por la identificación de manifestaciones de las enfermedades con una perspectiva de género; de esa manera, quizás, algún día, sea posible hablar de neuroginecología.

\section{REFERENCIAS}

1. O'Neal MA. A review of women's neurology. Am J Med. 2018; 131 (7): 735-744.

2. Guanyabens-Busca N, Casado-Ruiz V, Gine-Serven E, Palomeras E, Muriana D, Boix-Quintana E et al. Encefalitis antirreceptor de NMDA. Diagnóstico y tratamiento precoz en pacientes con sintomatología psicótica aguda-subaguda. Rev Neurol. 2019; 68 (1): 18-22.

3. Dalmau J, Graus F. Antibody-mediated encephalitis. N Engl J Med. 2018; 378 (9): 840-851.

4. Titulaer MJ, McCracken L, Gabilondo I, Armangué T, Glaser C, lizuka $\mathrm{T}$ et al. Treatment and prognostic factors for long-term outcome in patients with anti-NMDA receptor encephalitis: an observational cohort study. Lancet Neurol. 2013; 12 (2): 157-165.

5. Seki M, Suzuki S, lizuka T, Shimizu T, Nihei Y, Suzuki N et al. Neurological response to early removal of ovarian teratoma in anti-NMDAR encephalitis. J Neurol Neurosurg Psychiatry. 2008; 79 (3): 324-326.

6. Armangue T, Leypoldt F, Málaga I, Raspall-Chaure M, Marti I, Nichter $C$ et al. Herpes simplex virus encephalitis is a trigger of brain autoimmunity. Ann Neurol. 2014; 75 (2): 317-323.

7. Leypoldt F, Titulaer MJ, Aguilar E, Walther J, Bonstrup M, Havemeister S et al. Herpes simplex virus-1 encephalitis can trigger anti-NMDA receptor encephalitis: case report. Neurology. 2013; 81 (18): 1637-1639.

8. Hu X, Wang J, Dong W, Fang Q, Hu L, Liu C. A meta-analysis of polycystic ovary syndrome in women taking valproate for epilepsy. Epilepsy Res. 2011; 97 (1-2): 73-82.

9. Sahota P, Prabhakar S, Kharbanda PS, Bhansali A, Jain V, Das CP et al. Seizure type, antiepileptic drugs, and reproductive endocrine dysfunction in Indian women with epilepsy: a cross-sectional study. Epilepsia. 2008; 49 (12): 2069-2077.

10. Verrotti A, D'Egidio C, Mohn A, Coppola G, Parisi P, Chiarelli F. Antiepileptic drugs, sex hormones, and PCOS. Epilepsia. 2011; 52 (2): 199-211.

11. Bushnell C, Saposnik G. Evaluation and management of cerebral venous thrombosis. Continuum (Minneap Minn). 2014; 20 (2): 335-351.

12. Ruiz-Sandoval JL, Chiquete E, Bañuelos-Becerra LJ, Torres-Anguiano C, González-Padilla C, Arauz A et al. Cerebral venous thrombosis in a Mexican multicenter registry of acute cerebrovascular disease: the RENAMEVASC study. J Stroke Cerebrovasc Dis. 2012; 21 (5): 395-400.

13. van Vlijmen EF, Veeger NJ, Middeldorp S, Hamulyák K, Prins MH, Büller HR et al. Thrombotic risk during oral contraceptive use and pregnancy in women with factor $\mathrm{V}$ Leiden or prothrombin mutation: a rational approach to contraception. Blood. 2011; 118 (8): 20552061; quiz 2375.

14. Practice Committee of the American Society for Reproductive Medicine. Electronic address: ASRM@asrm.org; Practice Committee of the American Society for Reproductive Medicine. Combined hormonal contraception and the risk of venous thromboembolism: a guideline. Fertil Steril. 2017; 107 (1): 43-51.

15. Dulicek P, Ivanova E, Kostal M, Sadilek P, Beranek M, Zak P et al. Analysis of risk factors of stroke and venous thromboembolism in females with oral contraceptives use. Clin Appl Thromb Hemost. 2018; 24 (5): 797-802. 